\title{
Protein-Hydrogel Interactions in Tissue Engineering: Mechanisms and Applications
}

\author{
Silviya P. Zustiak, PhD, ${ }^{1}$ Yunqian Wei, $M S^{2}$, and Jennie B. Leach, $\mathrm{PhD}^{2}$
}

Recent advances in our understanding of the sophistication of the cellular microenvironment and the dynamics of tissue remodeling during development, disease, and regeneration have increased our appreciation of the current challenges facing tissue engineering. As this appreciation advances, we are better equipped to approach problems in the biology and therapeutics of even more complex fields, such as stem cells and cancer. To aid in these studies, as well as the established areas of tissue engineering, including cardiovascular, musculoskeletal, and neural applications, biomaterials scientists have developed an extensive array of materials with specifically designed chemical, mechanical, and biological properties. Herein, we highlight an important topic within this area of biomaterials research, protein-hydrogel interactions. Due to inherent advantages of hydrated scaffolds for soft tissue engineering as well as specialized bioactivity of proteins and peptides, this field is well-posed to tackle major needs within emerging areas of tissue engineering. We provide an overview of the major modes of interactions between hydrogels and proteins (e.g., weak forces, covalent binding, affinity binding), examples of applications within growth factor delivery and three-dimensional scaffolds, and finally future directions within the area of hydrogel-protein interactions that will advance our ability to control the cell-biomaterial interface.

\section{Overview of Protein-Hydrogel Interaction Mechanisms}

A S WE BEGIN to understand more about the in vivo cellular milieu and strive to recapitulate more of its features, protein-hydrogel interactions are gaining increasing importance in tissue engineering. Protein-conjugated hydrogels are now routinely used as a simplified mimic of the extracellular matrix (ECM), where such cell populated constructs represent either platforms for basic discovery or fully functional tissue replacements. Whereas the value of hydrogel-based scaffolds has long been established for soft tissue engineering applications, the incorporation of various proteins in the scaffold structure has more recently been appreciated as beneficial toward eliciting a desired cell response, degradability, or manipulating the mechanical and physical properties of the scaffold itself. However, major concerns when incorporating proteins include the preservation of bioactivity as well as proper presentation for maximum desired effect.

This review provides an overview of strategies used to create protein-hydrogel conjugates, with emphasis on covalent and affinity interactions, but also touching upon weak interactions, such as adsorption. We focus on two applications of protein-hydrogel interactions in tissue engineering: immobilization of growth factors and conjugates for use as three-dimensional (3D) scaffolds for cell growth. Due to the nature of engineered tissues, which require a favorable cell environment, the emphasis will be on chemistries that are either nontoxic to cells or lead to nontoxic final products. In addition, because preservation of protein activity is essential, only water-based chemistries will be considered. The necessity to employ only water-based, nontoxic chemistries for the design of cell-compatible biomaterials, particularly in the context of 3D scaffold preparations, poses rather rigid constrains on materials processing. Here, the cell compatibility of the materials extends beyond chemical versatility of the hydrogels; it encompasses the design of physical and bioactive environments that are capable of eliciting specific interactions from biological systems. The authors recommend several comprehensive reviews ${ }^{1-3}$ stressing the importance and associated limitations of designing bioactive and biocompatible hydrogels.

\section{Adsorption, electrostatic, and other weak interactions}

Weak interactions, such as electrostatic binding or repulsion, hydrogen bonding, and van der Waals forces typically underline physisorption and chemisorption of biomolecules onto hydrogels. Adsorption has been extensively explored as means of incorporating biomolecules into scaffolds for release in tissue engineering applications. For example, a solution of vascular endothelial growth factor

\footnotetext{
${ }^{1}$ National Institute of Child Health and Human Development, National Institutes of Health, Bethesda, Maryland.

${ }^{2}$ Department of Chemical, Biochemical and Environmental Engineering, University of Maryland, Baltimore County, Baltimore, Maryland.
} 
(VEGF) loaded onto freeze-dried collagen gels allowed the growth factor to adsorb onto the hydrogel during hydration and swelling. Adsorption had also been used for loading bone morphogenic protein-2 (BMP-2) into various particulate vehicles ${ }^{4,5}$ and basic fibroblast growth factor into hydrogel matrices. ${ }^{6}$ In some cases, such as the adsorption of human serum albumin onto chitosan/alginate systems, electrostatic and hydrophobic forces, as well as surface topography, were found to affect protein adsorption synergistically. ${ }^{7}$

Hydrogen bonding is another weak interaction used in protein-polymer modifications, where plasma surface treatment can be used to introduce carboxylic functional groups to the polymer. ${ }^{8}$ Due to its reversible nature, hydrogen bonding is amenable to the creation of degradable polymer scaffolds. For example, the self-complimentary hydrogenbonding moieties (ureido-pyrimidinone or UPy groups) were utilized as the basis to assemble polymers and biomolecules (Fig. 1). ${ }^{9}$ In gels with polar and charged functionality, hydrogen bonding, electrostatic interactions, and van der Waals forces can all influence protein-hydrogel interactions. For example, $\mathrm{pH}$-sensitive insulin release was achieved with carboxylated chitosan-grafted nanoparticles. ${ }^{10}$
Though adsorption may be sufficient for in vitro applications, this approach is associated with challenges in vivo due to desorption and exchange with physiological fluid. Further, inherently adsorptive scaffolds may cause a long-term inflammation or fibrosis. Conversely, nonionic hydrophilic polymers, such as poly(ethylene glycol) (PEG), poly(vinyl alcohol), and polyacrylamide, are considered inert to protein adsorption and other methods for efficient immobilization are generally required.

\section{Affinity interactions}

Inspired by the mechanism by which bioactive molecules are stored and presented in native ECM, interactions based on affinity between two biomolecules pose the advantage of tailoring the biomolecule release rate and mechanism. In hydrogels, affinity molecules or peptides are used to incorporate functionalized biomolecules, such as growth factors, into the gel structure.

Naturally derived affinity molecules. Sulfated glycosaminoglycans, such as heparin sulfate, are one class of ECM molecules that bind growth factors in vivo via electrostatic
A

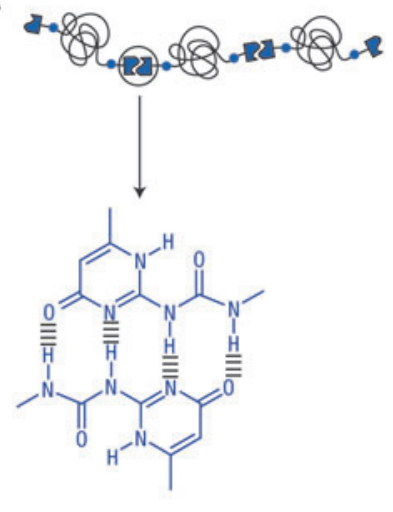

B

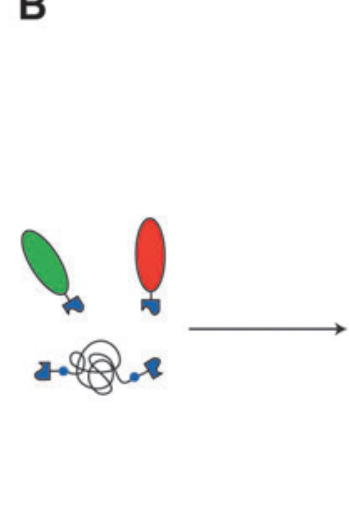

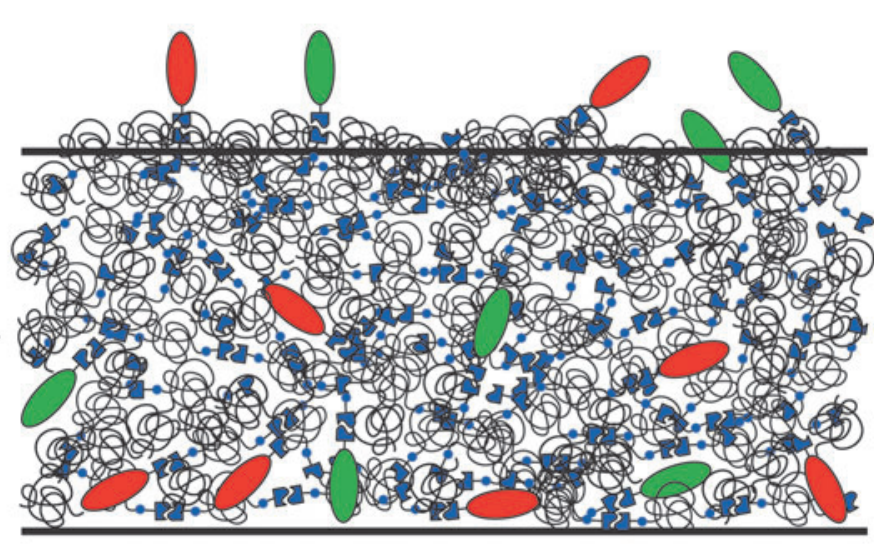

C<smiles>Cc1cc(=O)nc(NC(=O)NCC(=O)NC(CCCNC(=N)N)C(=O)NCC(=O)NC(CC(=O)O)C(=O)N[C@@H](CO)C(=O)O)[nH]1</smiles><smiles>Cc1cc(=O)nc(NC(=O)NCCCCCCNC(=O)N2CCCC2C(=O)NC(Cc2cnc[nH]2)C(=O)N[C@@H](CO)C(=O)NC(CCCNC(=N)N)C(=O)N[C@@H](CC(N)=O)C(=O)O)[nH]1</smiles><smiles>CCOCCOC(=O)CCCCCCOC(=O)NCCCCCCNC(=O)Nc1nc(=O)cc(C)[nH]1</smiles>

FIG. 1. (A) The self-complementary hydrogen-bonding ureido-pyrimidinone (UPy) moiety in a supramolecular polymer. (B) The modular approach to constructing bioactive materials with various properties by mixing different UPy-functionalized biomolecules (green and red moieties) with UPy-polymers. (C) As building blocks for these materials, two UPy-functionalized peptides (UPy-GRGDS and UPy-PHSRN) were used in combination with an oligocaprolactone functionalized on both ends with UPy-units (PCLdiUPy). Image reproduced from Dankers et al. ${ }^{9}$ Color images available online at www.liebertpub.com/teb 
interactions. Due to their high content of functional groups available for modification with crosslinking sites, glycosaminoglycans have been utilized for several decades to modulate growth factor release in hydrogels. In 1991, Edelman et al. developed heparin-modified beads to achieve a controlled release of basic fibroblast growth factor by affinity binding. ${ }^{11}$ Since this work, heparin has been extensively explored in biomaterials for affinity interactions with a number of growth factors, ${ }^{12,13}$ including hepatocyte growth factor (HGF) ${ }^{14,15}$ neurotrophin-3, ${ }^{16}$ BMP-2, ${ }^{17}$ and VEGF. ${ }^{18}$ Other uses of heparin-based affinity include assembly of noncovalent 3D networks for enhancing cellular affinity ${ }^{19}$ or inducing stem cell differentiation. ${ }^{20}$ Another glycosaminoglycan, the negatively charged chondroitin sulfate, has demonstrated affinity for several positively charged growth factors, including nerve growth factor (NGF). ${ }^{21}$

Hyaluronic acid (HA) and alginate are also naturally derived biomolecules and have structural similarities to heparin. Sulfated HA-alginate biomaterials have exhibited affinity binding to VEGF, platelet-derived growth factor-BB, and transforming growth factor- $\beta 1$ (TGF- $\beta 1) .^{22}$ Alginate hydrogels are simple injectable hydrogels, capable of controlled delivery of multiple proteins, while preserving the properties of the alginate. $^{23}$ For example, alginate hydrogels were used to achieve dual delivery of insulin-like growth factor-1 and HGF to promote myocardial repair in a rat model of acute myocardial infarction, ${ }^{24}$ as well as for dual delivery of TGF- $\beta 1$ and $\mathrm{BMP}-4$ to induce articular cartilage regeneration in a rabbit model of subchondral defect (Fig. 2). ${ }^{25}$

Protein components of the ECM also have affinity to growth factors and have been explored in affinity binding biomaterials. For example, collagens I, III, V, and VI have affinity to $\mathrm{HGF}^{26}$ and fibronectin and vitronectin domains can bind several growth factors, including $\mathrm{HGF}^{27}$

Affinity peptides and other synthetic affinity molecules. A variety of affinity peptides have been identified which are derived from ligand-receptor binding motifs and ECM structural molecules. In comparison to large naturally derived biomolecules, short peptide sequences are generally easier to synthesize and incorporate into hydrogels, and offer more control over material properties. For example, Maynard and Hubbell identified a sulfated heparin-mimetic tetrapeptide that binds to $\mathrm{VEGF}^{28}$; Anseth and coworkers, identified affinity peptides that bind to TGF- $\beta 1,{ }^{29}$ and Hudalla and Murphy used a peptide derived from the heparinbinding domain of FGF-2 to sequester heparin proteoglycans. ${ }^{30,31}$ The general approach to incorporate peptides into hydrogels is to utilize their various functional groups (i.e., amines, carboxyls, alcohols, thiols) to bind to the hydrogel structure (see also section Covalent interactions). For example, peptides containing Cys can react via Michael-type addition of thiol to vinyl sulfone or acrylate groups present in hydrogel polymers. ${ }^{32}$ Due to their versatility and relatively simple structure, the kinetics of a variety of peptide-based affinity interactions have been explored. Notably, Lin and Anseth determined the relationship between the peptide structure and affinity binding to the basic fibroblast growth factor within PEG hydrogels. ${ }^{33}$ Sakiyama-Elbert and coworkers identified peptides with affinity to NGF and also developed a mathematical model to describe the kinetics of the affinity binding reaction. ${ }^{34}$ Vulic and Shoichet uncovered

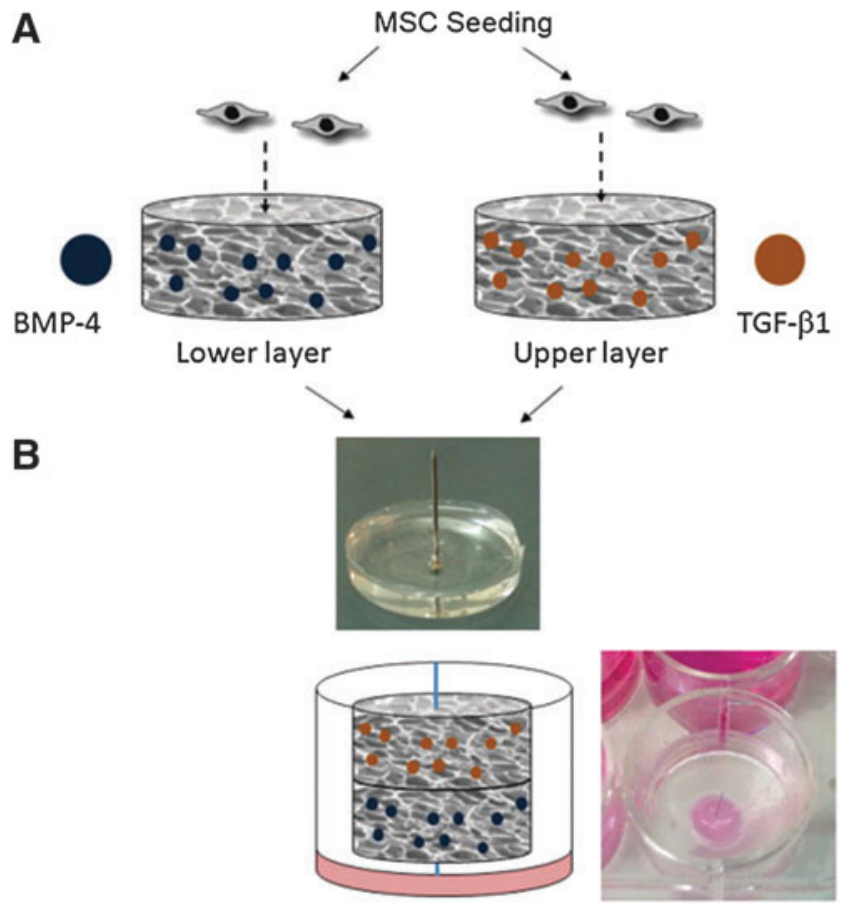

FIG. 2. A scheme describing the construction of a bilayer affinity-binding alginate scaffold. Transforming growth factor- $\beta$ (TGF- $\beta 1$ ) and bone morphogenic protein-4 (BMP-4) were affinity-bound to alginate sulfate in macroporous alginate scaffolds. After cell seeding and a culture of 2 days (A), the seeded scaffolds were combined together by their assembly on a stainless steel pin placed perpendicular to a supporting poly(dimethyl siloxane) layer (B). Image reproduced from Re'em et al. ${ }^{25}$ Color images available online at www.liebertpub.com/teb

the specific binding of the Src homology 3 domain expressed in growth factors to proline-rich peptides, ${ }^{35}$ and Wang et al. developed a new collagen mimetic peptide that binds to collagen type I via ionic interactions and shows specific affinity to VEGF. ${ }^{36}$

A variety of synthetic affinity molecules have been developed for affinity chromatography and are readily applied to biomaterial systems as well. For example, metal-ion chelation chemistry has been utilized to functionalize hydrogels with affinity motifs. Lin and Metters modified gels with iminodiacetic acid groups that chelate with hexa-histidine tagged protein. ${ }^{37}$ This approach may provide a specific advantage for controlled release as the growth factor can be dissociated and released on demand by the addition of metal ions. Further, multiple ligand-metal pairs may be implemented to provide cascades of multiple growth factors. ${ }^{38}$

\section{Covalent interactions}

Covalent tethering of peptides and proteins onto hydrogels is desirable in a variety of tissue engineering and controlled release applications and has been utilized with natural as well as synthetic hydrogels. ${ }^{39,40}$ Covalent attachment of biomolecules is generally more stable, provides greater control over biomolecule presentation and release, and is able to generate superior hydrogel mechanical properties as compared to physical entrapment, adsorption, or affinity interactions. ${ }^{41,42}$ 
For the covalent fuctionalization of hydrogels with proteins, one must consider reaction conditions that sustain the protein structure and activity. Protein immobilization reactions generally require aqueous conditions, since organic solvents may cause denaturation and degradation. Many of the widely used protein chemistries are nonspecific in that they target amines (N-terminus, Lys), carboxyls (C-terminus, Asp, Glu), and hydroxyls (Ser, Thr, Tyr). The presence of multiple available residues for modification makes these covalent interactions attractive for a wide range of applications, such as fluorescent labeling. However, in other applications, such as tethering of growth factors or adhesive motifs, random modifications can affect the proper biomolecule presentation by either altering protein conformation or by sterically blocking the protein-active site. Thus, random modification can lead to heterogeneous and poorly reproducible substrates. We highlight several immobilization strategies that have shown particular advantage for reaction specificity, patterning, or preserving bioactivity and biocompatibility. For an excellent resource on these and other covalent tethering chemistries, we recommend Hermanson's "Bioconjugate Techniques". ${ }^{43}$

Carbodiimide and succinimide chemistries. The carboxylactivating agent 1-ethyl-3-(3-dimethylaminopropyl) carbodiimide (EDC) is a water soluble carbodiimide widely used for coupling to primary amines, yielding stable amide bonds (Fig. 3). Carbodiimide chemistry has been applied to modify amine-terminated polycaprolactone-PEG nanofibers with epidermal growth factor, ${ }^{44}$ to immobilize VEGF onto collagen scaffolds, ${ }^{45}$ and to immobilize NGF onto gelatin-tricalcium phosphate membranes. ${ }^{46}$ EDC reacts with a carboxyl to form an amine-reactive O-acylisourea intermediate. Since this intermediate rapidly hydrolyzes in an aqueous environment, EDC is often used in combination with N-hydroxysuccinimide (NHS) or sulfo-NHS to increase coupling efficiency by creating a more stable intermediate. ${ }^{43}$ Reaction conditions, such as $\mathrm{pH}$, are key determinants of reaction outcome, with optimal $\mathrm{pH}$ from 4.7 to 6.0 , even though reaction can occur at mildly alkaline conditions, but with a slower rate and lower yields. Potential side reactions to note when considering EDC/NHS chemistry with proteins include the reaction of EDC with Cys sulfhydryls and Tyr phenols as well as the reaction of sulfo-NHS with the imidazolyl group in His. ${ }^{43}$

One challenge to EDC chemistry stems from the fact that the carbodiimide, due to its nonspecific nature, may cause inter- or intraprotein reactions and alter biomolecule activity or cause aggregation. To address this drawback, step immobilization can be used to first activate polymer carboxyls, and then react with protein amines; this approach was effective for modifying collagen gels to present uniform or gradient patterns of immobilized VEGF. ${ }^{47,48}$

Photo-immobilization. In many cases, it is beneficial to use photoreactive heterobifunctional crosslinkers, where one terminus is tailored to react with the desired functional groups (usually amines on proteins) and the other terminus is photoreactive (e.g., phenyl azide, benzophenone or diazo compound). These linkers react nonspecifically with ultraviolet (UV) light by creating singlet nitrenes that undergo insertion into $\mathrm{C}-\mathrm{H}, \mathrm{N}-\mathrm{H}$, and other bonds. Such crosslinkers are commercially available and their chemistry is simple, effective, and inexpensive. N-sulfosuccinimidyl-6-(4'-azido-

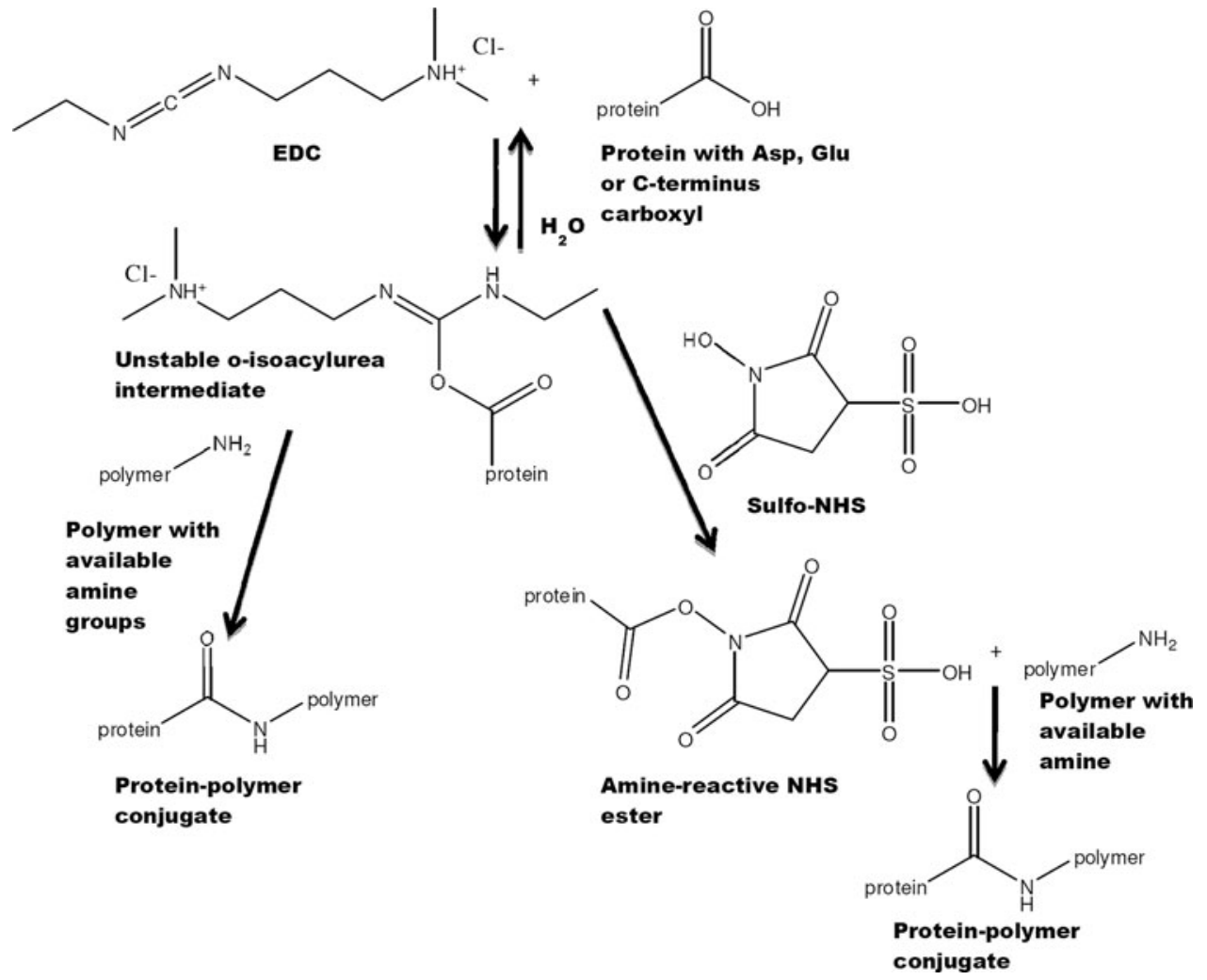

FIG. 3. Schematic representation of 1-ethyl-3-(3dimethylaminopropyl) carbodiimide (EDC)/ sulfo-Nhydroxysuccinimide (NHS) chemistry. In this example, a stable amide bond is formed between the carboxylate group of a protein and the amine groups of a polymer, but due to the modular nature of the reaction, protein amines can also be reacted with polymer carboxylates. Sulfo-NHS is added to improve reaction yield by forming a semistable reaction intermediate. 
2'-nitrophenylamino) hexanoate (sulfo-SANPAH, Table 1), which contains a photoactivatable phenyl azide and an amine-reactive NHS is one example of this class of crosslinkers. Sulfo-SANPAH has been widely used to conjugate biomolecules onto polyacrylamide gels for studying cellular response to substrate stiffness. ${ }^{49-51}$

Alternatively, photochemistry can be combined with EDC chemistry, as in the case with the azidophenyl-derivatized polyallylamine method developed by Matsuda and Sugawara $^{52}$ and modified by Ito et al., ${ }^{53,54}$ where the protein is rendered photoreactive by modifying carboxyls with polyallylamine using EDC chemistry. This chemistry has been used for the immobilization of growth factors onto poly(dimethyl siloxane $)^{55}$ and glass. ${ }^{56}$ Another type of photoreactive heterobifunctional crosslinkers contains an NHS or a succinimidyl carbonate group for conjugation to protein amines and a photoreactive acrylate or methacrylate group. Acrylates undergo free radical polymerization in the presence of a photoinitiator and UV irradiation. This chemistry is widely applied for growth factor immobilization, where the crosslinkers may contain a spacer arm to improve growth factor accessibility to the cells. ${ }^{57-60}$ Similar conjugations have been used to create protein-polymer and peptide-polymer conjugates to yield photopolymerizable biomimetic hydrogels. ${ }^{61-63}$

Photoimmobilization of proteins is an attractive strategy with many advantages, such as facile spatial and temporal control over reaction kinetics as well as rapid reaction conditions. However, to avoid the concern of generating active radical species during UV irradiation, which may affect protein bioactivity and cell viability, reaction conditions, such as UV exposure time and photoinitiator type and concentration must be optimized. ${ }^{64}$

Click chemistry. Click chemistry is a general concept that describes reactions that are high yielding, stereospecific, highly versatile, simple to perform and purify, and occur in benign solvents. ${ }^{65}$ Originally, click chemistry was introduced to accelerate drug discovery and testing, but it is increasingly becoming utilized in tissue engineering. To address a major drawback of conventional click chemistries, namely, the use of cytotoxic copper or ruthenium catalysts, copper-free click chemistry has been developed. ${ }^{66,67}$ For example, Nimmo et al. utilized click chemistry to design a one-step, aqueousbased method to crosslink HA hydrogels for use in tissue engineering. ${ }^{68}$ Anseth and coworkers adapted a click chemistry to perform spatial and temporal patterning of polypeptides onto PEG hydrogels to pattern 3D cell microenvironments (Fig. 4). ${ }^{69,70}$

Other chemistries. There are a large number of other chemistries used to create protein-hydrogel conjugates of which we will only attempt to describe a few. One such reaction is the Michael-type addition pioneered for use in tissue engineering by Elbert and Hubbell ${ }^{71}$ and Lutolf and Hubbell. ${ }^{72}$ In this reaction, unsaturated double bonds of chemical moieties, such as vinyl sulfone, acrylate, or methacrylate react under basic conditions with a thiol typically

Table 1. Crosslinkers Used for Protein-Hydrogel Conjugation

\begin{tabular}{|c|c|c|}
\hline Crosslinker name & Crosslinker structure & Comments \\
\hline Sulfo-SANPAH ${ }^{123,124}$ & & $\begin{array}{l}\text { Water-soluble, amine-reactive and light } \\
\text { activatable crosslinker based on aryl azide } \\
\text { chemistry; noncleavable }\end{array}$ \\
\hline Glutaraldehyde $\mathrm{e}^{125-128}$ & & $\begin{array}{l}\text { Amine-to-amine crosslinker; highly toxic } \\
\text { to cells; water-soluble }\end{array}$ \\
\hline Genipin $^{129-132}$ & & $\begin{array}{l}\text { Natural nontoxic amine-to-amine crosslinker; } \\
\text { derived from gardenia fruit; stable; water- } \\
\text { soluble; improves mechanical properties of } \\
\text { naturally occurring hydrogels, such as } \\
\text { collagen Type I }\end{array}$ \\
\hline $\mathrm{MBS}^{133}$ & & $\begin{array}{l}\text { Nontoxic amine-to-sulfhydryl crosslinker; } \\
\text { reactive at physiological conditions; not } \\
\text { soluble in water }\end{array}$ \\
\hline $\mathrm{SMCC}^{87,134}$ & & $\begin{array}{l}\text { Nontoxic amine-to-sulfhydryl crosslinker; } \\
\text { stable maleimide groups; reactive at } \\
\text { physiological conditions; rapid reaction } \\
\text { kinetics; not soluble in water }\end{array}$ \\
\hline $\begin{array}{l}\text { 2-(2-pyridin-2-yldisulfanyl)ethyl } \\
\text { 2-(methacrylamido)acetate (PDMA) }\end{array}$ & & $\begin{array}{l}\text { Modify protein amines to bear } \\
\text { methacrylamide groups; link is reducible } \\
\text { due to presence of disulfide bond }\end{array}$ \\
\hline
\end{tabular}

SANPAH, N-sulfosuccinimidyl-6-(4'-azido-2'-nitrophenylamino) hexanoate; MBS, m-maleimidobenzoyl-N-hydroxysuccinimide ester; SMCC, succinimidyl-4-(N-maleimidomethyl)cyclohexane-1-carboxylate. 

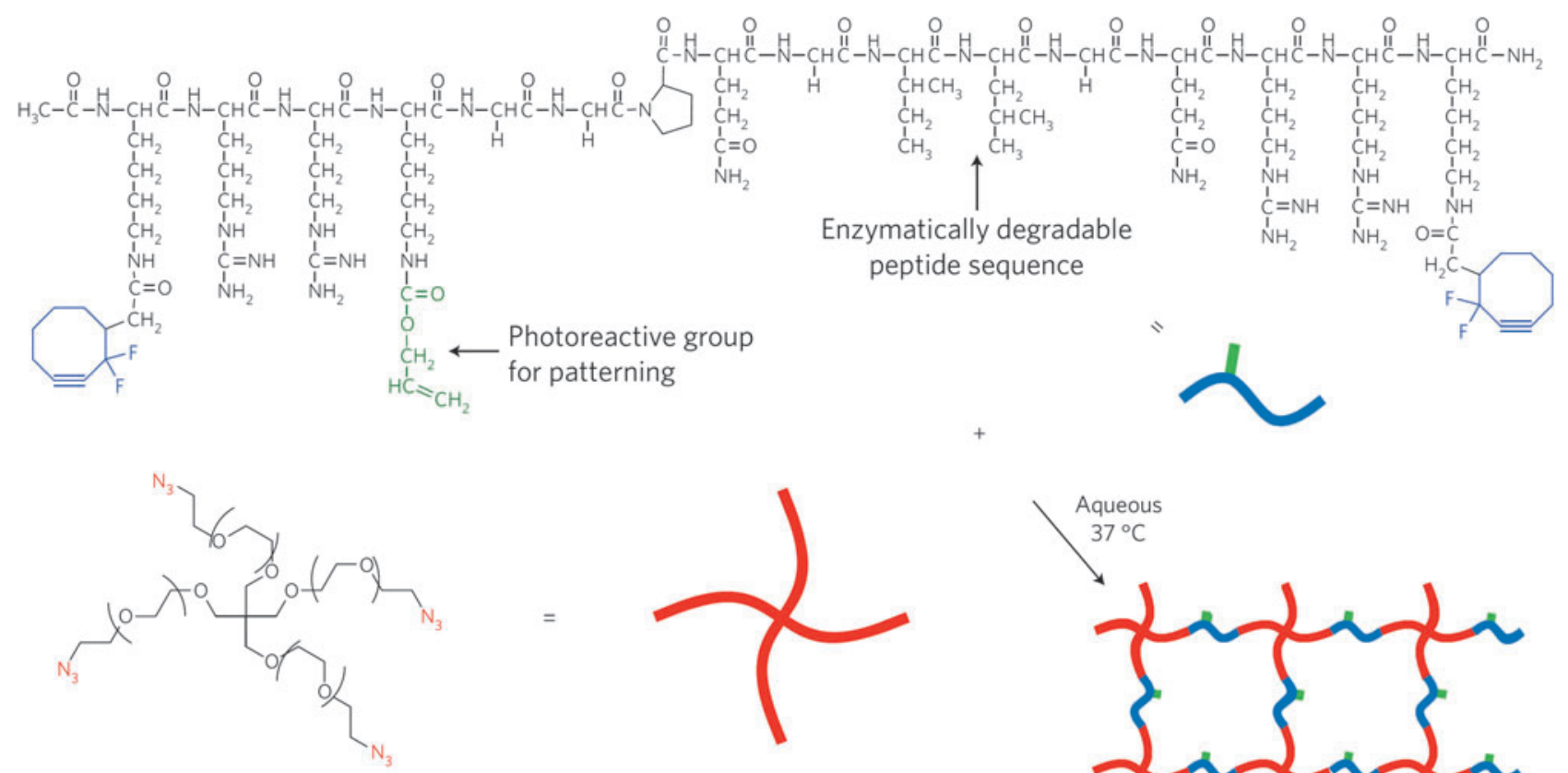

Poly(ethylene glycol) Tetra-azide Mol. wt.: - 10,000
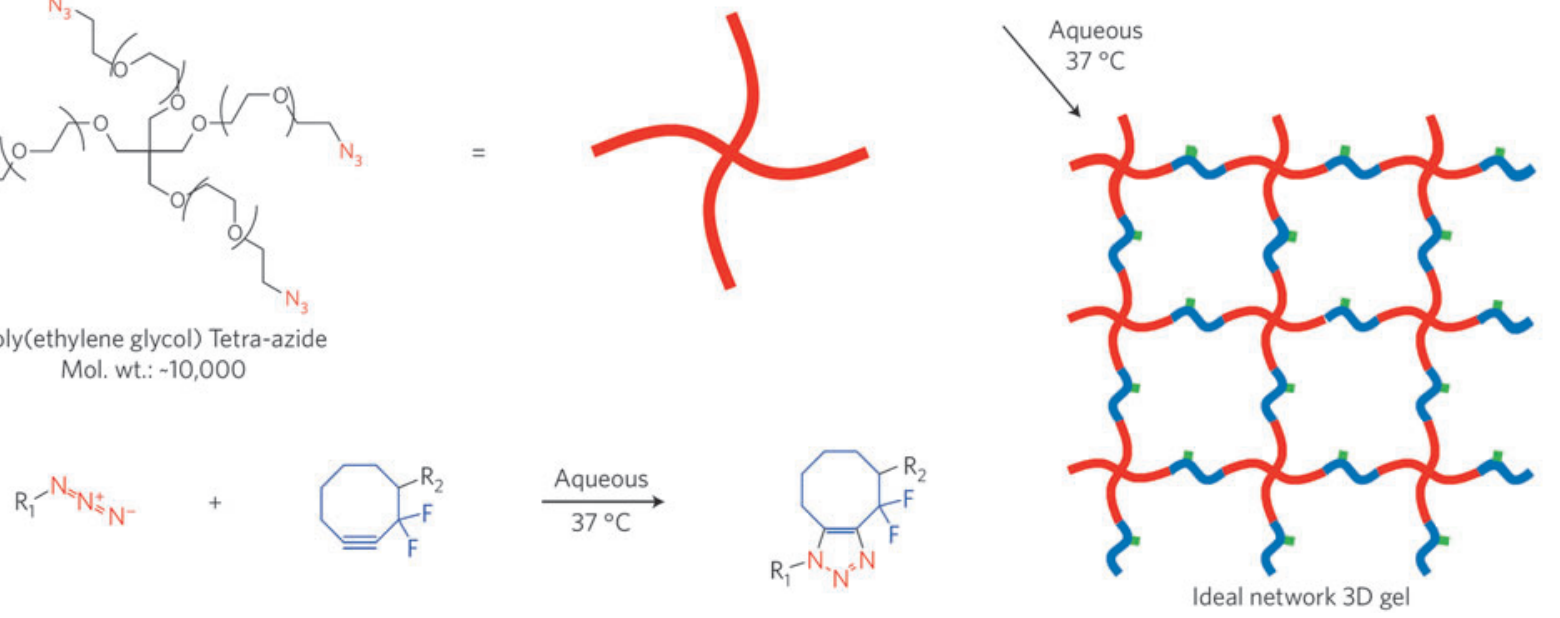

FIG. 4. Click-functionalized macromolecular precursors undergo the Cu-free [3+2] Huisgen cycloaddition to form a 3D ideal network hydrogel through a step-growth polymerization mechanism. Here, two orthogonal click chemistries are used: one for hydrogel formation and another for biochemical patterning within the preformed material. The modular aspect of these reactions allows for independent control of the network structure and chemistry, and facile incorporation of biological molecules. Image reproduced from DeForest et al. ${ }^{70}$ Color images available online at www.liebertpub.com/teb

provided by Cys. For peptides, the reactivity of the thiol can be modulated by the presence of charged amino acids in the direct vicinity of the Cys. ${ }^{73}$ This chemistry is biocompatible and selective, and therefore ideal for protein conjugation and has been successfully used for conjugation of polymers to Cys-terminated peptides, ${ }^{74,75}$ genetically engineered growth factors with an added Cys, ${ }^{76,77}$ and other proteins. ${ }^{78,79}$

Homo- and hetero-bifunctional crosslinkers, despite their inherent nonspecific reactivity, are very useful for the crosslinking of polymers and proteins. Thus, in addition to linkers that have been applied for decades, such as glutaraldehyde, new crosslinkers (Table 1) are being developed with further improvements over existing technologies. Main advantages of the novel crosslinkers include lack of toxicity to cells, as well as improved versatility by incorporation of specific moieties, such as acrylates or disulfides, that permit controlled protein release, gelation strategies and kinetics, or gel degradation. For example, genipin, a naturally occurring crosslinker, has toxicity levels 10,000-fold lower than glutaraldehyde. ${ }^{80}$ Further, the acrylate functionality, which is responsible for photopolymerization of PEG-diacrylate gels, is utilized for several protein-hydrogel crosslinking reactions, including cleavable protein hydrogel crosslinkers (2-(2pyridin-2-yldisulfanyl)ethyl 2-(methacrylamido)acetate in Table 1$)^{81,82}$ and degradable hydrogels, where redox poly- merization strategies allows for in-situ cell encapsulation. ${ }^{83}$ HA has been similarly modified with methacrylate to obtain gels that encompass the range of physiologically relevant mechanical properties, while maintaining HA cell receptors. ${ }^{84,85}$

\section{Tissue Engineering Applications of Protein-Hydrogel Interactions}

Protein-hydrogel interactions are desirable in a variety of tissue engineering applications, including sustained, localized, or targeted protein delivery, induction of specific cell signaling, and control of stem cell fate. We focus here on the two most common applications: immobilization of growth factors and polymer-protein conjugates for use as 3D scaffolds for cell growth, where the protein presents cell binding domains or degradation sites.

\section{Immobilization of growth factors}

Growth factors, which are involved in cellular proliferation, differentiation, and tissue regeneration, can be supplied exogenously via solution injection or by immobilization onto scaffolds. ${ }^{40}$ The latter method is generally more efficient in promoting the desired cell outcome, while preserving bioactivity and stability, which in turn prolongs growth factor 
signaling and minimizes costs of growth factor therapeutics. Superior growth factor performance upon immobilization has been demonstrated by Chiu and Radisic, where VEGF tethered onto collagen scaffolds was associated with a higher endothelial cell proliferation versus treatment with VEGF in a solution. ${ }^{86}$ In addition, the immobilization method itself is important for growth factor performance, as demonstrated by Park et al., who determined that BMP-2 immobilized covalently onto chitosan nanofibers had higher bioactivity, promoted greater cell proliferation, alkaline phosphatase activity, and calcium deposition when compared with nanofibers with absorbed BMP-2. ${ }^{87}$

The concentration of the growth factor influences cell response, and when varying growth factor concentration is presented as a gradient, it has the potential to guide directional cell responses. For example, Davis et al. demonstrated that increased concentration of BMP-2 adsorbed onto polymer scaffolds enhanced the osteogenic response of human mesenchymal stem cells, ${ }^{4}$ while Odedra et al. found that VEGF gradients on collagen scaffolds promoted directional endothelial cell migration. ${ }^{48}$ Further, Moore et al. revealed that neurotrophin gradients on synthetic gels promoted guided neurite outgrowth from chick dorsal root ganglia neurons. ${ }^{88}$

Growth factor tethering is especially favored for in-vivo scaffold applications, where it offers the additional advantage of localizing the effect of the growth factor within the scaffold itself rather than allow it to freely diffuse into the surrounding tissue. Further, immobilized growth factors have a physiological significance, as both bound and free growth factors are present in vivo. It is thought that cells first respond to the soluble growth factor, migrate toward its source, and then respond to the higher concentration of bound protein at the source. For example, Miyagi et al. covalently immobilized VEGF onto collagen scaffolds to promote neovascularization in vivo. ${ }^{89}$ The authors showed that scaffolds containing VEGF had greater blood vessel density than the control scaffolds with no VEGF, due to increased endothelial cell infiltration and proliferation. ${ }^{89}$ Further, Choi et al. demonstrated that the epithelial growth factor covalently immobilized onto polycaprolactone-PEG scaffolds promoted keratinocyte differentiation and resulted in superior wound healing in vivo than control groups with the soluble growth factor. ${ }^{44}$ Alberti and coworkers compared various methods of immobilizing the leukemia inhibitory factor onto hydrogels, including covalent attachment, covalent attachment via a flexible PEG spacer arm, and noncovalent binding (Fig. 5). They determined that the spacer arm increased growth factor accessibility and resulted in greater mouse embryonic stem cell pluripotency. ${ }^{90}$

\section{Protein-hydrogel copolymers for use as $3 D$ cell scaffolds}

In tissue engineering applications, cell scaffolds ideally should mimic the natural structure of the tissue they are replacing, while providing a structural support for the cells. Polymer-protein conjugates are especially promising for use as tissue engineering scaffolds for a variety of reasons, including the addition of specific biological activity to already biocompatible substrates.
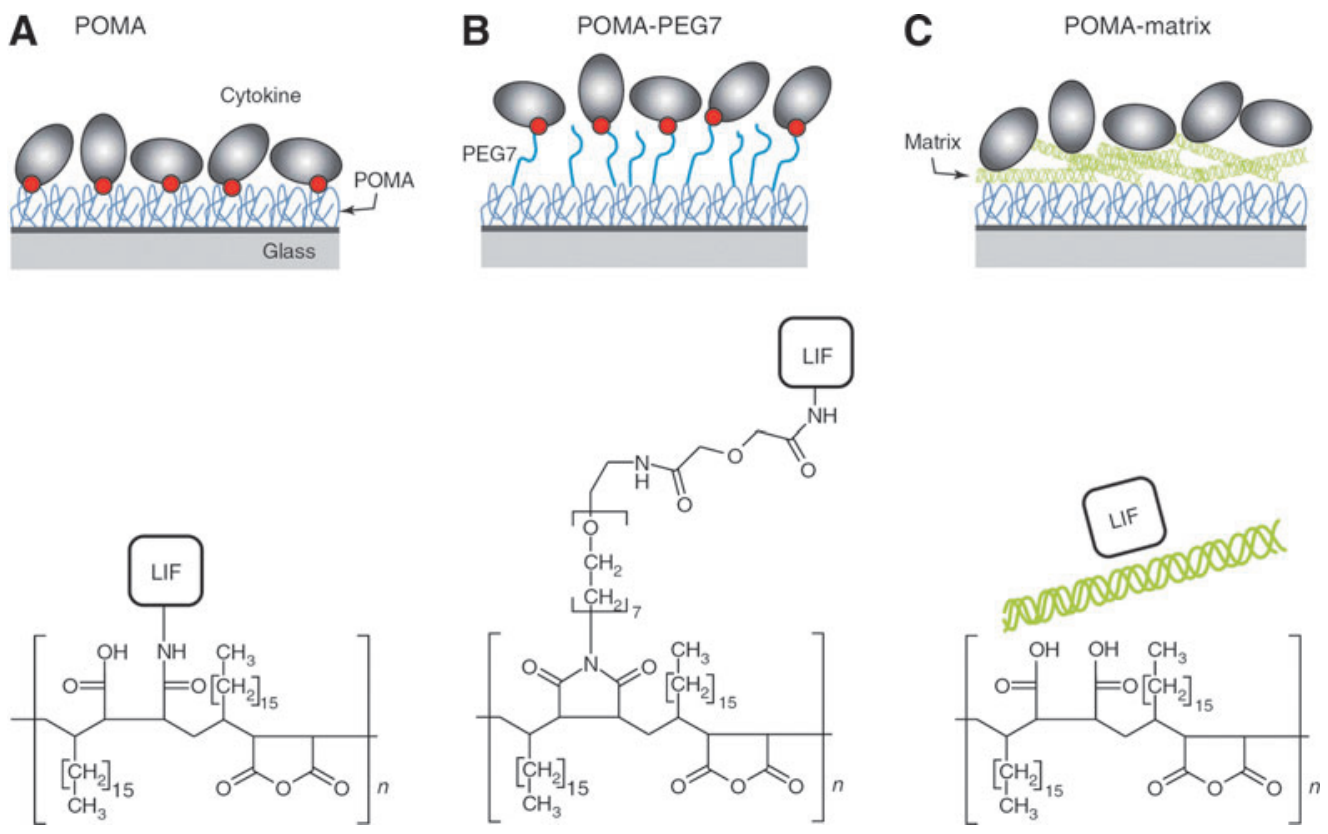

FIG. 5. (A-C) A cytokine, leukemia inhibitory factor (LIF), was immobilized by covalent attachment to a hydrogel composed of poly(octadecene-alt-maleic anhydride) (POMA) (A), covalent attachment to flexible poly(ethylene glycol) (PEG) spacer arms tethered to POMA (B) and noncovalent binding to extracellular matrix coating deposited on top of hydrolyzed POMA (C). Red circles indicate covalent bond. Note that POMA was covalently bound to amino-functionalized glass substrates and is the key component of the immobilization platform. POMA and POMA-PEG7 surfaces were coated with matrix for cell culture experiments (omitted from the figure for clarity). Only one covalent bond between the protein and the surface is shown, although more bonds are possible. Chemical structures depict the POMA layer and the immobilization mode of LIF. Image reproduced from Alberti et al. ${ }^{90}$ Color images available online at www.liebertpub.com/teb 
Conjugates of proteins and synthetic hydrogels. Synthetic biomaterials are widely used in tissue engineering because they offer precise control over a wide range of scaffold mechanical properties. ${ }^{85,91,92}$ Protein modification is especially advantageous for synthetic materials because proteins may provide intrinsic biological activity, such as cell adhesion or proteolytically degradable sites to typically inert polymers.

PEG, arguably the most widely used synthetic polymer in soft tissue engineering, has been conjugated to a variety of proteins to form biosynthetic hydrogel scaffolds. For example, Almany and Seliktar developed PEG-fibrinogen scaffolds as 3D environments for tissue regeneration therapies. ${ }^{78}$ The fibrinogen provided cell attachment motifs as well as proteolytic sensitivity for degradation, while PEG was responsible for the superior hydrogel elastic modulus. ${ }^{78}$ Comparing the properties of three different PEG-protein copolymers, GonenWadmany et al. reported cell spreading and migration on PEG-fibrinogen and PEG-collagen gels, and not on PEGbovine serum albumin gels due to lack of cell adhesion motifs on the bovine serum albumin backbone. ${ }^{93}$ Interestingly, the composite hydrogels also showed different elasticity, swelling, and degradability based on the incorporated protein, underscoring the importance of the molecular relationship between the polymer and the protein. ${ }^{93}$

Composites of collagen and polyanhydrides, such as polylactic acid, polyglycolic acid, and polycaprolactone, have been synthesized as nanofibrous matrices, ${ }^{94-96}$ grafted copolymers, ${ }^{97}$ and composite gels ${ }^{98-100}$ and are widely used in bone and cartilage tissue engineering, because of their similarity to natural bone or cartilage in main composition and hierarchical nanostructure. For example, these composite gels have been used in the form of a polylactic-glycolic acid sponge prepared with incorporated collagen microsponges in the pores, where the collagen facilitated homogeneous cell seeding and subsequent cell differentiation. ${ }^{101}$ Electrospun collagen/polycaprolactone materials have also been used as nerve guide conduits in vivo where they were able to support the nerve regeneration through an 8-mm sciatic nerve gap in adult rats, thus approaching the effectiveness of the nerve autograft. ${ }^{94}$ Collagen-poly(lactic acidco-caprolactone) hybrid scaffolds have been used for bladder tissue regeneration, where the hybrid hydrogels exhibited a lower inflammatory reaction and degradation times than scaffolds without collagen. ${ }^{102}$

Peptides are commonly incorporated into hydrogels, including motifs derived from the ECM, such as the cell adhesive peptide $\mathrm{RGD}^{83,103}$ as well as peptides susceptible to matrix metalloproteinase cleavage that allow proteolytic gel degradation. $^{32,104}$ Methods to incorporate peptide ligands onto biomaterials have been reviewed extensively and, thus, can be found elsewhere. ${ }^{39,105}$

Conjugates of proteins and natural hydrogels. Because of their intrinsic biocompatibility, natural biomaterials are also very attractive for use in tissue engineering despite their relatively low mechanical strength. Usually, protein-hydrogel matrices are meant to either elicit a specific biological response from the cells (e.g., growth factor immobilization) or to improve the composite hydrogel mechanical, biochemical, or physical properties over the individual materials alone. ${ }^{106-108}$ The most common natural materials used in tissue engineering include HA, chitosan, collagen, fibrinogen, fibrin, and agarose. ${ }^{109}$

A variety of composites based on natural materials have been developed to address a major challenge in the construction of 3D scaffolds for tissue engineering; namely, the development of highly porous scaffolds with interconnected pores. ${ }^{110}$ Various collagen/HA/chitosan scaffolds with highly porous interconnected structures were manufactured by varying ratios between the constituents to find the optimal conditions for tissue engineering applications. ${ }^{111}$ Chitosan-HA-based hydrogels were created as injectable, biodegradable, and glucose-responsive hydrogels to deliver insulin in vitro. ${ }^{112}$ Highly porous collagen/HA composite hydrogels have also been developed as a model of the mammary gland, ${ }^{113}$ as a matrix for invertebral disk repair, ${ }^{114,115}$ and as a scaffold to study glioma cell invasion. ${ }^{116}$ Further, collagen/fibrin composite matrices were used as vascular constructs because of their superior mechanical strength in comparison to each of the components alone. ${ }^{117}$

\section{Future Directions}

While there is an array of well-established chemistries for physical, covalent, or affinity conjugation of proteins, one of the major areas in need of further development, especially in terms of growth factor conjugation, is the presentation of biomolecules. The majority of available conjugation chemistries are nonspecific, thus compromising molecule bioactivity by binding site unavailability due to orientation or steric hindrance. The nonspecific chemistries also raise issues of robustness, heterogeneities, as well as unwanted side interactions, such as competitive binding of media or serum proteins. These limitations are beginning to be addressed by adding tags to the biomolecule to ensure binding specificity or by adding spacer arms between the hydrogel and the protein to avoid steric hindrance. Examples of tags and linkers include Cys, ${ }^{118} \mathrm{Fc}^{119}$ polyhistidine, ${ }^{120,121}$ as well as de novo-designed coil-tagged chimeras. ${ }^{122}$ Overall, the development of more protein-hydrogel interactions, as well as the accumulation of knowledge about their effect on cell fate, will enable the design of engineered tissues that better mimic the in-vivo environment, as well as tissues that can be safely translated into the clinic.

\section{Acknowledgments}

We acknowledge NIH-NINDS R01NS065205 and funds from the Intramural Research Program of The Eunice Kennedy Shriver National Institute of Child Health and Human Development, NIH for supporting this work.

\section{Disclosure Statement}

No competing financial interests exist.

\section{References}

1. Lutolf, M.P., Gilbert, P.M., and Blau, H.M. Designing materials to direct stem-cell fate. Nature 462, 433, 2009.

2. Lutolf, M.P., and Hubbell, J.A. Synthetic biomaterials as instructive extracellular microenvironments for morphogenesis in tissue engineering. Nat Biotechnol 23, 47, 2005.

3. Seliktar, D. Designing cell-compatible hydrogels for biomedical applications. Science 336, 1124, 2012. 
4. Davis, H.E., Case, E.M., Miller, S.L., Genetos, D.C., and Leach, J.K. Osteogenic response to BMP-2 of hMSCs grown on apatite-coated scaffolds. Biotechnol Bioeng 108, 2727, 2011.

5. Xie, G., Sun, J., Zhong, G., Liu, C., and Wei, J. Hydroxyapatite nanoparticles as a controlled-release carrier of BMP-2: absorption and release kinetics in vitro. J Mater Sci Mater Med 21, 1875, 2010.

6. Lefler, A., and Ghanem, A. Development of bFGF-chitosan matrices and their interactions with human dermal fibroblast cells. J Biomater Sci Polym Ed 20, 1335, 2009.

7. Martins, G.V., Merino, E.G., Mano, J.F., and Alves, N.M. Crosslink effect and albumin adsorption onto chitosan/alginate multilayered systems: an in situ QCM-D study. Macromol Biosci 10, 1444, 2010.

8. Wang, S., Zhang, Y., Wang, H., and Dong, Z. Preparation, characterization and biocompatibility of electrospinning heparin-modified silk fibroin nanofibers. Int J Biol Macromol 48, 345, 2011.

9. Dankers, P.Y., Harmsen, M.C., Brouwer, L.A., van Luyn, M.J., and Meijer, E.W. A modular and supramolecular approach to bioactive scaffolds for tissue engineering. Nat Mater 4, 568, 2005.

10. Cui, F., Qian, F., Zhao, Z., Yin, L., Tang, C., and Yin, C. Preparation, characterization, and oral delivery of insulin loaded carboxylated chitosan grafted poly(methyl methacrylate) nanoparticles. Biomacromolecules 10, 1253, 2009.

11. Edelman, E.R., Mathiowitz, E., Langer, R. Klagsbrun, M. Controlled and modulated release of basic fibroblast growth factor. Biomaterials 12, 619, 1991.

12. Oh, S.H., Kim, T.H., and Lee, J.H. Creating growth factor gradients in three dimensional porous matrix by centrifugation and surface immobilization. Biomaterials 32, 8254, 2011.

13. Nie, T., Baldwin, A., Yamaguchi, N., and Kiick, K.L. Production of heparin-functionalized hydrogels for the development of responsive and controlled growth factor delivery systems. J Control Release 122, 287, 2007.

14. Kim, M., Lee, J.Y., Jones, C.N., Revzin, A., and Tae, G. Heparin-based hydrogel as a matrix for encapsulation and cultivation of primary hepatocytes. Biomaterials 31, 3596, 2010.

15. Ruvinov, E., Leor, J., and Cohen, S. The effects of controlled HGF delivery from an affinity-binding alginate biomaterial on angiogenesis and blood perfusion in a hindlimb ischemia model. Biomaterials 31, 4573, 2010.

16. Taylor, S.J., McDonald, J.W., and Sakiyama-Elbert, S.E. Controlled release of neurotrophin-3 from fibrin gels for spinal cord injury. J Control Release 98, 281, 2004.

17. Jeon, O., Powell, C., Solorio, L.D., Krebs, M.D., and Alsberg, E. Affinity-based growth factor delivery using biodegradable, photocrosslinked heparin-alginate hydrogels. J Control Release 154, 258, 2011.

18. Tae, G., Scatena, M., Stayton, P.S., and Hoffman, A.S. PEGcross-linked heparin is an affinity hydrogel for sustained release of vascular endothelial growth factor. J Biomater Sci Polym Ed 17, 187, 2006.

19. Lee, J., Yoo, J.J., Atala, A., and Lee, S.J. Controlled heparin conjugation on electrospun poly(epsilon-caprolactone)/ gelatin fibers for morphology-dependent protein delivery and enhanced cellular affinity. Acta Biomater 8, 2549, 2012.

20. Tan, H., Zhou, Q., Qi, H., Zhu, D., Ma, X., and Xiong, D. Heparin interacting protein mediated assembly of nanofibrous hydrogel scaffolds for guided stem cell differentiation. Macromol Biosci 12, 621, 2012.
21. Conovaloff, A., and Panitch, A. Characterization of a chondroitin sulfate hydrogel for nerve root regeneration. J Neural Eng 8, 056003, 2011.

22. Freeman, I., and Cohen, S. The influence of the sequential delivery of angiogenic factors from affinity-binding alginate scaffolds on vascularization. Biomaterials 30, 2122, 2009.

23. Re'em, T., Kaminer-Israeli, Y., Ruvinov, E., and Cohen, S. Chondrogenesis of hMSC in affinity-bound TGF-beta scaffolds. Biomaterials 33, 751, 2012.

24. Ruvinov, E., Leor, J., and Cohen, S. The promotion of myocardial repair by the sequential delivery of IGF-1 and HGF from an injectable alginate biomaterial in a model of acute myocardial infarction. Biomaterials 32, 565, 2011.

25. Re'em, T., Witte, F., Willbold, E., Ruvinov, E., and Cohen, S. Simultaneous regeneration of articular cartilage and subchondral bone induced by spatially presented TGF-beta and BMP-4 in a bilayer affinity binding system. Acta Biomater 8, 3283, 2012.

26. Schuppan, D., Schmid, M., Somasundaram, R., Ackermann, R., Ruehl, M., Nakamura, T., and Riecken, E.O. Collagens in the liver extracellular matrix bind hepatocyte growth factor. Gastroenterology 114, 139, 1998.

27. Rahman, S., Patel, Y., Murray, J., Patel, K.V., Sumathipala, R., Sobel, M., and Wijelath, E.S. Novel hepatocyte growth factor (HGF) binding domains on fibronectin and vitronectin coordinate a distinct and amplified Met-integrin induced signalling pathway in endothelial cells. BMC Cell Biol 6, 8, 2005.

28. Maynard, H.D., and Hubbell, J.A. Discovery of a sulfated tetrapeptide that binds to vascular endothelial growth factor. Acta Biomater 1, 451, 2005.

29. McCall, J.D., Lin, C.C., and Anseth, K.S. Affinity peptides protect transforming growth factor beta during encapsulation in poly(ethylene glycol) hydrogels. Biomacromolecules 12, 1051, 2011.

30. Hudalla, G.A., and Murphy, W.L. Immobilization of peptides with distinct biological activities onto stem cell culture substrates using orthogonal chemistries. Langmuir 26, $6449,2010$.

31. Hudalla, G.A., and Murphy, W.L. Biomaterials that regulate growth factor activity via bioinspired interactions. Adv Funct Mater 21, 1754, 2011.

32. Lutolf, M.P., Lauer-Fields, J.L., Schmoekel, H.G., Metters, A.T., Weber, F.E., Fields, G.B., and Hubbell, J.A. Synthetic matrix metalloproteinase-sensitive hydrogels for the conduction of tissue regeneration: engineering cell-invasion characteristics. Proc Natl Acad Sci U S A 100, 5413, 2003.

33. Lin, C.C., and Anseth, K.S. Controlling affinity binding with peptide-functionalized poly(ethylene glycol) hydrogels. Adv Funct Mater 19, 2325, 2009.

34. Willerth, S.M., Johnson, P.J., Maxwell, D.J., Parsons, S.R., Doukas, M.E., and Sakiyama-Elbert, S.E. Rationally designed peptides for controlled release of nerve growth factor from fibrin matrices. J Biomed Mater Res A 80, 13, 2007.

35. Vulic, K., and Shoichet, M.S. Tunable growth factor delivery from injectable hydrogels for tissue engineering. J Am Chem Soc 134, 882, 2012.

36. Wang, A.Y., Leong, S., Liang, Y.C., Huang, R.C., Chen, C.S., and $\mathrm{Yu}$, S.M. Immobilization of growth factors on collagen scaffolds mediated by polyanionic collagen mimetic peptides and its effect on endothelial cell morphogenesis. Biomacromolecules 9, 2929, 2008. 
37. Lin, C.C., and Metters, A.T. Metal-chelating affinity hydrogels for sustained protein release. J Biomed Mater Res A 83, 954, 2007.

38. Lin, C.C., and Metters, A.T. Bifunctional monolithic affinity hydrogels for dual-protein delivery. Biomacromolecules $\mathbf{9}$, 789, 2008.

39. Hersel, U., Dahmen, C., and Kessler, H. RGD modified polymers: biomaterials for stimulated cell adhesion and beyond. Biomaterials 24, 4385, 2003.

40. Masters, K.S. Covalent growth factor immobilization strategies for tissue repair and regeneration. Macromol Biosci 11, 1149, 2011.

41. Giraudier, S., Hellio, D., Djabourov, M., and Larreta-Garde, V. Influence of weak and covalent bonds on formation and hydrolysis of gelatin networks. Biomacromolecules 5, 1662, 2004.

42. Jeong, K.J., and Panitch, A. Interplay between covalent and physical interactions within environment sensitive hydrogels. Biomacromolecules 10, 1090, 2009.

43. Hermanson, G.T. Bioconjugate Techniques, 2nd Edn. San Diego, CA: Academic Press, 2008.

44. Choi, J.S., Leong, K.W., and Yoo, H.S. In vivo wound healing of diabetic ulcers using electrospun nanofibers immobilized with human epidermal growth factor (EGF). Biomaterials 29, 587, 2008.

45. Shen, Y.H., Shoichet, M.S., and Radisic, M. Vascular endothelial growth factor immobilized in collagen scaffold promotes penetration and proliferation of endothelial cells. Acta Biomater 4, 477, 2008.

46. Chen, P.R., Chen, M.H., Lin, F.H., and Su, W.Y. Release characteristics and bioactivity of gelatin-tricalcium phosphate membranes covalently immobilized with nerve growth factors. Biomaterials 26, 6579, 2005.

47. Chiu, L.L., Weisel, R.D., Li, R.K., and Radisic, M. Defining conditions for covalent immobilization of angiogenic growth factors onto scaffolds for tissue engineering. J Tissue Eng Regen Med 5, 69, 2011.

48. Odedra, D., Chiu, L.L., Shoichet, M., and Radisic, M. Endothelial cells guided by immobilized gradients of vascular endothelial growth factor on porous collagen scaffolds. Acta Biomater 7, 3027, 2011.

49. Kandow, C.E., Georges, P.C., Janmey, P.A., and Beningo, K.A. Polyacrylamide hydrogels for cell mechanics: steps toward optimization and alternative uses. Methods Cell Biol 83, 29, 2007.

50. Mih, J.D., Sharif, A.S., Liu, F., Marinkovic, A., Symer, M.M., and Tschumperlin, D.J. A multiwell platform for studying stiffness-dependent cell biology. PLoS One 6, e19929, 2011.

51. Jacot, J.G., McCulloch, A.D., and Omens, J.H. Substrate stiffness affects the functional maturation of neonatal rat ventricular myocytes. Biophys J 95, 3479, 2008.

52. Matsuda, T., and Sugawara, T. Development of surface photochemical modification method for micropatterning of cultured cells. J Biomed Mater Res 29, 749, 1995.

53. Ito, Y., Chen, G., and Imanishi, Y. Micropatterned immobilization of epidermal growth factor to regulate cell function. Bioconjug Chem 9, 277, 1998.

54. Ito, Y., Chen, G., Imanishi, Y., Morooka, T., Nishida, E., Okabayashi, Y., and Kasuga, M. Differential control of cellular gene expression by diffusible and non-diffusible EGF. J Biochem 129, 733, 2001.

55. Gomez, N., Lu, Y., Chen, S., and Schmidt, C.E. Immobilized nerve growth factor and microtopography have distinct effects on polarization versus axon elongation in hippocampal cells in culture. Biomaterials 28, 271, 2007.

56. Ogiwara, K., Nagaoka, M., Cho, C.S., and Akaike, T. Effect of photo-immobilization of epidermal growth factor on the cellular behaviors. Biochem Biophys Res Commun 345, 255, 2006.

57. Porter, A.M., Klinge, C.M., and Gobin, A.S. Covalently grafted VEGF165 in hydrogel models up-regulates the cellular pathways associated with angiogenesis. Am J Physiol Cell Physiol 301, C1086, 2011.

58. Mann, B.K., Schmedlen, R.H., and West, J.L. Tethered-TGFbeta increases extracellular matrix production of vascular smooth muscle cells. Biomaterials 22, 4390, 2001.

59. DeLong, S.A., Moon, J.J., and West, J.L. Covalently immobilized gradients of bFGF on hydrogel scaffolds for directed cell migration. Biomaterials 26, 3227, 2005.

60. Leslie-Barbick, J.E., Moon, J.J., and West, J.L. Covalentlyimmobilized vascular endothelial growth factor promotes endothelial cell tubulogenesis in poly(ethylene glycol) diacrylate hydrogels. J Biomater Sci Polym Ed 20, 1763, 2009.

61. Hern, D.L., and Hubbell, J.A. Incorporation of adhesion peptides into nonadhesive hydrogels useful for tissue resurfacing. J Biomed Mater Res 39, 266, 1998.

62. Scott, R., Marquardt, L., and Willits, R.K. Characterization of poly(ethylene glycol) gels with added collagen for neural tissue engineering. J Biomed Mater Res A 93, 817, 2010.

63. Dikovsky, D., Bianco-Peled, H., and Seliktar, D. The effect of structural alterations of PEG-fibrinogen hydrogel scaffolds on 3-D cellular morphology and cellular migration. Biomaterials 27, 1496, 2006.

64. Lin, C.C., Sawicki, S.M., and Metters, A.T. Free-radicalmediated protein inactivation and recovery during protein photoencapsulation. Biomacromolecules 9, 75, 2008.

65. Kolb, H.C., Finn, M.G., and Sharpless, K.B. Click chemistry: diverse chemical function from a few good reactions. Angew Chem Int Ed Engl 40, 2004, 2001.

66. Baskin, J.M., Prescher, J.A., Laughlin, S.T., Agard, N.J., Chang, P.V., Miller, I.A., Lo, A., Codelli, J.A., and Bertozzi, C.R. Copper-free click chemistry for dynamic in vivo imaging. Proc Natl Acad Sci U S A 104, 16793, 2007.

67. Laughlin, S.T., Baskin, J.M., Amacher, S.L., and Bertozzi, C.R. In vivo imaging of membrane-associated glycans in developing zebrafish. Science 320, 664, 2008.

68. Nimmo, C.M., Owen, S.C., and Shoichet, M.S. Diels-Alder Click cross-linked hyaluronic acid hydrogels for tissue engineering. Biomacromolecules 12, 824, 2011.

69. Polizzotti, B.D., Fairbanks, B.D., and Anseth, K.S. Threedimensional biochemical patterning of click-based composite hydrogels via thiolene photopolymerization. Biomacromolecules 9, 1084, 2008.

70. DeForest, C.A., Polizzotti, B.D., and Anseth, K.S. Sequential click reactions for synthesizing and patterning threedimensional cell microenvironments. Nat Mater 8, 659, 2009.

71. Elbert, D.L., and Hubbell, J.A. Conjugate addition reactions combined with free-radical cross-linking for the design of materials for tissue engineering. Biomacromolecules 2, 430, 2001.

72. Lutolf, M.P., and Hubbell, J.A. Synthesis and physicochemical characterization of end-linked poly(ethylene glycol)-co-peptide hydrogels formed by Michael-type addition. Biomacromolecules 4, 713, 2003.

73. Lutolf, M.P., Tirelli, N., Cerritelli, S., Cavalli, L., and Hubbell, J.A. Systematic modulation of Michael-type reactivity 
of thiols through the use of charged amino acids. Bioconjug Chem 12, 1051, 2001.

74. Zustiak, S.P., and Leach, J.B. Hydrolytically degradable poly(ethylene glycol) hydrogel scaffolds with tunable degradation and mechanical properties. Biomacromolecules 11, 1348, 2010.

75. Zustiak, S.P., Durbal, R., and Leach, J.B. Influence of celladhesive peptide ligands on poly(ethylene glycol) hydrogel physical, mechanical and transport properties. Acta Biomater 6, 3404, 2010.

76. Leipzig, N.D., Wylie, R.G., Kim, H., and Shoichet, M.S. Differentiation of neural stem cells in three-dimensional growth factor-immobilized chitosan hydrogel scaffolds. Biomaterials 32, 57, 2011.

77. Zisch, A.H., Lutolf, M.P., Ehrbar, M., Raeber, G.P., Rizzi, S.C., Davies, N., Schmokel, H., Bezuidenhout, D., Djonov, V., Zilla, P., and Hubbell, J.A. Cell-demanded release of VEGF from synthetic, biointeractive cell ingrowth matrices for vascularized tissue growth. FASEB J 17, 2260, 2003.

78. Almany, L., and Seliktar, D. Biosynthetic hydrogel scaffolds made from fibrinogen and polyethylene glycol for 3D cell cultures. Biomaterials 26, 2467, 2005.

79. Oss-Ronen, L., and Seliktar, D. Polymer-conjugated albumin and fibrinogen composite hydrogels as cell scaffolds designed for affinity-based drug delivery. Acta Biomater 7, 163, 2011.

80. Sung, H.W., Chang, W.H., Ma, C.Y., and Lee, M.H. Crosslinking of biological tissues using genipin and/or carbodiimide. J Biomed Mater Res A 64, 427, 2003.

81. Verheyen, E., Delain-Bioton, L., der Wal, S., El Morabit, N., Hennink, W.E., and van Nostrum, C.F. Protein macromonomers for covalent immobilization and subsequent triggered release from hydrogels. J Control Release 148, e18, 2010.

82. Verheyen, E., Delain-Bioton, L., van der Wal, S., el Morabit, N., Barendregt, A., Hennink, W.E., and van Nostrum, C.F. Conjugation of methacrylamide groups to a model protein via a reducible linker for immobilization and subsequent triggered release from hydrogels. Macromol Biosci 10, 1517, 2010.

83. Chien, H.W., Tsai, W.B., and Jiang, S. Direct cell encapsulation in biodegradable and functionalizable carboxybetaine hydrogels. Biomaterials 33, 5706, 2012.

84. Hachet, E., Van Den Berghe, H., Bayma, E., Block, M.R., and Auzely-Velty, R. Design of biomimetic cell-interactive substrates using hyaluronic acid hydrogels with tunable mechanical properties. Biomacromolecules 13, 1818, 2012.

85. Leach, J.B., Bivens, K.A., Collins, C.N., and Schmidt, C.E. Development of photocrosslinkable hyaluronic acid-polyethylene glycol-peptide composite hydrogels for soft tissue engineering. J Biomed Mater Res A 70, 74, 2004.

86. Chiu, L.L., and Radisic, M. Scaffolds with covalently immobilized VEGF and angiopoietin-1 for vascularization of engineered tissues. Biomaterials 31, 226, 2010.

87. Park, Y.J., Kim, K.H., Lee, J.Y., Ku, Y., Lee, S.J., Min, B.M., and Chung, C.P. Immobilization of bone morphogenetic protein-2 on a nanofibrous chitosan membrane for enhanced guided bone regeneration. Biotechnol Appl Biochem 43, 17, 2006

88. Moore, K., MacSween, M., and Shoichet, M. Immobilized concentration gradients of neurotrophic factors guide neurite outgrowth of primary neurons in macroporous scaffolds. Tissue Eng 12, 267, 2006.

89. Miyagi, Y., Chiu, L.L., Cimini, M., Weisel, R.D., Radisic, M., and Li, R.K. Biodegradable collagen patch with covalently immobilized VEGF for myocardial repair. Biomaterials 32, 1280, 2011.

90. Alberti, K., Davey, R.E., Onishi, K., George, S., Salchert, K., Seib, F.P., Bornhauser, M., Pompe, T., Nagy, A., Werner, C., and Zandstra, P.W. Functional immobilization of signaling proteins enables control of stem cell fate. Nat Methods 5, 645, 2008.

91. Hammouche, S., Hammouche, D., and McNicholas, M. Biodegradable bone regeneration synthetic scaffolds: in tissue engineering. Curr Stem Cell Res Ther 7, 134, 2012.

92. Fernandes, S., Kuklok, S., McGonigle, J., Reinecke, H., and Murry, C.E. Synthetic matrices to serve as niches for muscle cell transplantation. Cells Tissues Organs 195, 48, 2012.

93. Gonen-Wadmany, M., Oss-Ronen, L., and Seliktar, D. Protein-polymer conjugates for forming photopolymerizable biomimetic hydrogels for tissue engineering. Biomaterials 28, 3876, 2007.

94. Yu, W., Zhao, W., Zhu, C., Zhang, X., Ye, D., Zhang, W., Zhou, Y., Jiang, X., and Zhang, Z. Sciatic nerve regeneration in rats by a promising electrospun collagen/poly (epsilon-caprolactone) nerve conduit with tailored degradation rate. BMC Neurosci 12, 68, 2011.

95. Ngiam, M., Liao, S., Patil, A.J., Cheng, Z., Yang, F., Gubler, M.J., Ramakrishna, S., and Chan, C.K. Fabrication of mineralized polymeric nanofibrous composites for bone graft materials. Tissue Eng Part A 15, 535, 2009.

96. Zhang, Y.Z., Venugopal, J., Huang, Z.M., Lim, C.T., and Ramakrishna, S. Characterization of the surface biocompatibility of the electrospun PCL-collagen nanofibers using fibroblasts. Biomacromolecules 6, 2583, 2005.

97. Chen, J.P., Li, S.F., and Chiang, Y.P. Bioactive collagengrafted poly-L-lactic acid nanofibrous membrane for cartilage tissue engineering. J Nanosci Nanotechnol 10, 5393, 2010.

98. Liao, S.S., Cui, F.Z., Zhang, W., and Feng, Q.L. Hierarchically biomimetic bone scaffold materials: nano-HA/ collagen/PLA composite. J Biomed Mater Res B Appl Biomater 69, 158, 2004.

99. Liao, S.S., Cui, F.Z., and Zhu, Y. Osteoblasts adherence and migration through three-dimensional porous mineralized collagen based composite: nHAC/PLA. J Bioact Compat Polym 19, 117, 2004.

100. Liao, S.S., and Cui, F.Z. In vitro and in vivo degradation of mineralized collagen-based composite scaffold: nanohydroxyapatite/collagen/poly(L-lactide). Tissue Eng 10, 73, 2004.

101. Chen, G., Sato, T., Ushida, T., Ochiai, N., and Tateishi, T. Tissue engineering of cartilage using a hybrid scaffold of synthetic polymer and collagen. Tissue Eng 10, 323, 2004.

102. Engelhardt, E.M., Micol, L.A., Houis, S., Wurm, F.M., Hilborn, J., Hubbell, J.A., and Frey, P. A collagen-poly(lactic acid-co-varepsilon-caprolactone) hybrid scaffold for bladder tissue regeneration. Biomaterials 32, 3969, 2011.

103. Zhu, J., He, P., Lin, L., Jones, D.R., and Marchant, R.E. Biomimetic poly(ethylene glycol)-based hydrogels as scaffolds for inducing endothelial adhesion and capillary-like network formation. Biomacromolecules 13, 706, 2012.

104. Bahney, C.S., Hsu, C.W., Yoo, J.U., West, J.L., and Johnstone, B. A bioresponsive hydrogel tuned to chondrogenesis of human mesenchymal stem cells. FASEB J 25, 1486, 2011.

105. Shin, H., Jo, S., and Mikos, A.G. Biomimetic materials for tissue engineering. Biomaterials 24, 4353, 2003.

106. Lai, V.K., Lake, S.P., Frey, C.R., Tranquillo, R.T., and Barocas, V.H. Mechanical behavior of collagen-fibrin co-gels 
reflects transition from series to parallel interactions with increasing collagen content. J Biomech Eng 134, 011004, 2012.

107. Wang, X., Sang, L., Luo, D., and Li, X. From collagenchitosan blends to three-dimensional scaffolds: the influences of chitosan on collagen nanofibrillar structure and mechanical property. Colloids Surf B Biointerfaces 82, 233, 2011.

108. Rowe, S.L., and Stegemann, J.P. Microstructure and mechanics of collagen-fibrin matrices polymerized using ancrod snake venom enzyme. J Biomech Eng 131, 061012, 2009.

109. Silva, S.S., Mano, J.F., and Reis, R.L. Potential applications of natural origin polymer-based systems in soft tissue regeneration. Crit Rev Biotechnol 30, 200, 2010.

110. Yang, S., Leong, K.F., Du, Z., and Chua, C.K. The design of scaffolds for use in tissue engineering. Part I. Traditional factors. Tissue Eng 7, 679, 2001.

111. Lin, Y.C., Tan, F.J., Marra, K.G., Jan, S.S., and Liu, D.C. Synthesis and characterization of collagen/hyaluronan/ chitosan composite sponges for potential biomedical applications. Acta Biomater 5, 2591, 2009.

112. Tan, H., Rubin, J.P., and Marra, K.G. Injectable in situ forming biodegradable chitosan-hyaluronic acid based hydrogels for adipose tissue regeneration. Organogenesis 6, 173, 2010.

113. Davidenko, N., Campbell, J.J., Thian, E.S., Watson, C.J., and Cameron, R.E. Collagen-hyaluronic acid scaffolds for adipose tissue engineering. Acta Biomater 6, 3957, 2010.

114. Alini, M., Li, W., Markovic, P., Aebi, M., Spiro, R.C., and Roughley, P.J. The potential and limitations of a cell-seeded collagen/hyaluronan scaffold to engineer an intervertebral disc-like matrix. Spine 28, 446; discussion 453, 2003.

115. Calderon, L., Collin, E., Velasco-Bayon, D., Murphy, M., O'Halloran, D., and Pandit, A. Type II collagen-hyaluronan hydrogel-a step towards a scaffold for intervertebral disc tissue engineering. Eur Cell Mater 20, 134, 2010.

116. Yang, Y.L., Sun, C., Wilhelm, M.E., Fox, L.J., Zhu, J., and Kaufman, L.J. Influence of chondroitin sulfate and hyaluronic acid on structure, mechanical properties, and glioma invasion of collagen I gels. Biomaterials 32, 7932, 2011.

117. Cummings, C.L., Gawlitta, D., Nerem, R.M., and Stegemann, J.P. Properties of engineered vascular constructs made from collagen, fibrin, and collagen-fibrin mixtures. Biomaterials 25, 3699, 2004.

118. Backer, M.V., Patel, V., Jehning, B.T., Claffey, K.P., and Backer, J.M. Surface immobilization of active vascular endothelial growth factor via a cysteine-containing tag. Biomaterials 27, 5452, 2006.

119. Ogiwara, K., Nagaoka, M., Cho, C.S., and Akaike, T. Construction of a novel extracellular matrix using a new genetically engineered epidermal growth factor fused to IgG-Fc. Biotechnol Lett 27, 1633, 2005.

120. Kato, K., Sato, H., and Iwata, H. Immobilization of histidine-tagged recombinant proteins onto micropatterned surfaces for cell-based functional assays. Langmuir 21, 7071, 2005.

121. Nakaji-Hirabayashi, T., Kato, K., Arima, Y., and Iwata, H. Oriented immobilization of epidermal growth factor onto culture substrates for the selective expansion of neural stem cells. Biomaterials 28, 3517, 2007.

122. Boucher, C., St.-Laurent, G., Loignon, M., Jolicoeur, M., De Crescenzo, G., and Durocher, Y. The bioactivity and receptor affinity of recombinant tagged EGF designed for tissue engineering applications is defined by the nature and position of the tags. Tissue Eng Part A 14, 2069, 2008.
123. Tilghman, R.W., Cowan, C.R., Mih, J.D., Koryakina, Y., Gioeli, D., Slack-Davis, J.K., Blackman, B.R., Tschumperlin, D.J., and Parsons, J.T. Matrix rigidity regulates cancer cell growth and cellular phenotype. PLoS One 5, e12905, 2010.

124. Lin, Y.C., Tambe, D.T., Park, C.Y., Wasserman, M.R., Trepat, X., Krishnan, R., Lenormand, G., Fredberg, J.J., and Butler, J.P. Mechanosensing of substrate thickness. Phys Rev E Stat Nonlin Soft Matter Phys 82, 041918, 2010.

125. Annabi, N., Fathi, A., Mithieux, S.M., Martens, P., Weiss, A.S., and Dehghani, F. The effect of elastin on chondrocyte adhesion and proliferation on poly (epsilon-caprolactone)/ elastin composites. Biomaterials 32, 1517, 2011.

126. Ji, C., Annabi, N., Khademhosseini, A., and Dehghani, F. Fabrication of porous chitosan scaffolds for soft tissue engineering using dense gas $\mathrm{CO}_{2}$. Acta Biomater 7, 1653, 2011.

127. Huang, C., Chen, R., Ke, Q., Morsi, Y., Zhang, K., and Mo, $X$. Electrospun collagen-chitosan-TPU nanofibrous scaffolds for tissue engineered tubular grafts. Colloids Surf B Biointerfaces 82, 307, 2011.

128. Miranda, S.C., Silva, G.A., Hell, R.C., Martins, M.D., Alves, J.B., and Goes, A.M. Three-dimensional culture of rat BMMSCs in a porous chitosan-gelatin scaffold: a promising association for bone tissue engineering in oral reconstruction. Arch Oral Biol 56, 1, 2011.

129. Tan, H., DeFail, A., Rubin, J.P., Constance, R.C., and Marra, K.G. Novel multiarm PEG-based hydrogels for tissue engineering. J Biomed Mater Res Part A 92A, 979, 2009.

130. Schek, R.M., Michalek, A.J., and Iatridis, J.C. Genipincrosslinked fibrin hydrogels as a potential adhesive to augment intervertebral disc annulus repair. Eur Cell Mater 21, 373, 2011.

131. Bi, L., Cao, Z., Hu, Y., Song, Y., Yu, L., Yang, B., Mu, J., Huang, Z., and Han, Y. Effects of different cross-linking conditions on the properties of genipin-cross-linked chitosan/collagen scaffolds for cartilage tissue engineering. J Mater Sci Mater Med 22, 51, 2011.

132. Wang, C., Lau, T.T., Loh, W.L., Su, K., and Wang, D.A. Cytocompatibility study of a natural biomaterial crosslinker-genipin with therapeutic model cells. J Biomed Mater Res B Appl Biomater 97, 58, 2011.

133. Mochizuki, M., Kadoya, Y., Wakabayashi, Y., Kato, K., Okazaki, I., Yamada, M., Sato, T., Sakairi, N., Nishi, N., and Nomizu, M. Laminin-1 peptide-conjugated chitosan membranes as a novel approach for cell engineering. FASEB J 17, 875, 2003.

134. Zhang, Q., He, Q.F., Zhang, T.H., Yu, X.L., Liu, Q., and Deng, F.L. Improvement in the delivery system of bone morphogenetic protein-2: a new approach to promote bone formation. Biomed Mater 7, 045002, 2012.

Address correspondence to: Jennie B. Leach, PhD Department of Chemical, Biochemical and Environmental Engineering University of Maryland, Baltimore County Eng 314, 1000 Hilltop Circle Baltimore, MD 21250

E-mail: jleach@umbc.edu

Received: July 27, 2012

Accepted: September 26, 2012

Online Publication Date: November 13, 2012 